\title{
INVERSION ANALYSIS OF STATIC DISPLACEMENT DATA ASSOCIATED WITH THE ALASKA EARTHQUAKE OF 1964
}

\author{
Kaoru Mryashita and Mitsuhiro Matsu'ura \\ Geophysical Institute, Faculty of Science, University of Tokyo, Tokyo, Japan \\ (Received February 27, 1978; Revised May 12, 1978)
}

\begin{abstract}
By using a generalized inversion technique and the finite-element method, permanent changes in displacement caused by the Alaska earthquake of 1964 are analyzed to investigate a regional variation in the faulting mechanism of the extensive fracture system.

In section 2, the fracture system is modelled by a multiple-fault system composed of four rectangular faults in an elastic half-space. The results of the inversion analysis for the multiple-fault system show that the Alaska earthquake consists of a main faulting of a low-angle underthrust and a subsidiary surface faulting of a somewhat high-angle underthrust with a little left-lateral component. The main fault extends from Kodiak Island through Prince William Sound to Kayak Island with a total length of 600 $\mathrm{km}$, and the dip-angle $(j)$ and dislocation $(D)$ in the corresponding regions are $i=25^{\circ} \mathrm{NW}$ and $D=19 \mathrm{~m}, i=7^{\circ} \mathrm{NW}$ and $D=10 \mathrm{~m}$, and $\delta=20^{\circ} \mathrm{NE}$ and $D=8 \mathrm{~m}$ respectively. For the subsidiary fault, the optimal estimates are $i=31^{\circ} \mathrm{NW}$ and $D=12 \mathrm{~m}$. The strike direction $\left(\mathrm{N} 36^{\circ} \mathrm{E}\right)$ is parallel to that of the main fault in the Kodiak Island region.

In section 3, setting a vertical section to be perpendicular to the strike direction in the Kodiak Island region, the fracture system is treated in a framework of a plane-strain, finite-element approximation, where each fault surface is simulated by a sequence of dislocated double nodes. From the inversion analysis for the two-dimensional fault model, it was found that the dislocation along the main fault surface has a broad peak of $30 \mathrm{~m}$ at a depth of $20 \mathrm{~km}$ and decreases monotonously up to a depth of $60 \mathrm{~km}$. The profile in the shallower part is obscure, because of the lack of the data in the Gulf of Alaska. For the subsidiary fault, the dislocation has a peak of $12 \mathrm{~m}$ close to the earth's surface and decreases steeply at a depth of 10 $\mathrm{km}$. The profiles of the observed displacement fields across the fracture system are well interpreted by these dislocation functions varying with depth.
\end{abstract}

\section{Introduction}

Since its occurrence on March 28, 1964, the Alaska earthquake has been investigated in various aspects by a large number of seismologists, but there 
still remain some ambiguities on its faulting mechanism. One of the problems is the orientation of the fault surface, on which the main faulting occurred, and another is the regional variation in the faulting mechanism.

As to the former problem, PLAFKer (1965) inferred an underthrust motion on a low-angle plane dipping to the northwest from the geodetic measurements of the crustal deformations. This inference was supported by SAVAGE and Hastie (1966) and Hastie and SAVAge (1970) through a least-squares analysis of the static displacement data by using an elastic dislocation source model. The estimated results show that the fracture system consists of two dislocation surfaces, such as a main fault, which is a low-angle $\left(3.7^{\circ} \mathrm{NW}\right)$ underthrust with a little left-lateral motion, and a subsidiary surface fault on Montague Island with a dip-angle of $37^{\circ} \mathrm{NW}$. From an analysis of the radiation of long-period surface waves, KANAMORI (1970) has also proposed a reverse dip-slip fault dipping to $\mathrm{N} 24^{\circ} \mathrm{W}$ with an angle of $20^{\circ}$.

On the other hand, another type of fault-plane solution, that is a reverse dip-slip motion on a nearly vertical plane extending to a depth of $100-200 \mathrm{~km}$, was proposed by PRESS and JACKSON (1965) from the vertical displacement data and teleseismic strain data. This type of solution was preferred by HARDING and AlgERMissen (1969) rather than the low-angle thrust model, on the basis of an analysis of the P-wave first motion and $\mathrm{S}$-wave polarization data. By using the spectral amplitudes of surface waves and the line spectra of eigenvibrations, BEN-MENAHeM et al. (1972) have concluded as follows: these data permit both types of fault-plane solution, such as a low-angle $\left(5^{\circ}\right.$ $20^{\circ}$ ) reverse faulting and high-angle $\left(70^{\circ}-88^{\circ}\right)$ reverse faulting, but the latter model is more preferable as the real solution, when considering a reality of the best fitting dislocation profile across the fault plane.

Possibilities of a regional variation in the faulting mechanism of the Alaska earthquake have been suggested explicitly or implicitly by several authors. Taking the focal mechanism of one foreshock, the main shock and more than 25 aftershocks into consideration, STAUdER and Bollinger (1966) have pointed out a uniformity of the motion in the entire earthquake sequence and a systematic change in the fracture system corresponding to the change in trend of the tectonic features. WYSS and BRUNE (1967) have indicated that the character of the $\mathrm{P}$-wave portion of the seismograms of the main shock is interpreted in terms of an approximate multiple-event source mechanism composed of six events. HARDING and ALgermissen (1969) have referred to the possibility that the initial faulting in Prince William Sound is along a transform fault striking northwest near the eastern end of an Aleutian Island thrust fault system, and the subsequent fault motion in the vicinity of Kodiak Island is along the Aleutian underthrust.

Dealing with an extensive fracture system, it is necessary to take account 
of the regional variation in the faulting mechanism, since the character of the fracture is related to the tectonic features in the region concerned. From such a point of view, in section 2 , the vertical displacement data are analyzed for a multiple-fault system composed of four rectangular faults by using a method of "geodetic data inversion" developed by MATsu'ura (1977a). In section 3 , the dislocation profile along the fault surface is estimated by applying both a general linear inversion technique (JACKSON, 1972, 1973; WIGGINS, 1972) and plane-strain, finite-element modelling (Jungels and Frazier, 1973).

Several attempts have been made to interpret static displacement fields due to the occurrence of an earthquake in terms of a dislocation function varying along a complex fault surface (JUNGELS and Frazier, 1973; Alewine and Jordan, 1973; Alewine, 1974; MCCowan et al., 1977). In every case of these analyses, the dislocation function has been determined by using either the method of linear inversion or the least-squares procedure, under an assumption that the other presupposed fault parameters are adequate. However, the reliability of the estimated results critically depends on that of the presupposed fault parameters. In the present study, a configuration of the fault surface used for finite-element modelling is determined by taking account of both the results of the inversion analysis for the multiple-fault system and the geologic structure at the continental margin.

\section{Inversion Analysis for Multiple-Fault System}

The triangulation and levelling data for the crustal deformations caused by the Alaska earthquake of 1964 have been reported by PARKIN (1966) and PLAFKER (1969) respectively. The pattern of the vertical displacement field shows that the hinge line, which separates an elevated region on the seaward side and a subsiding region on the landward side, extends from Kodiak Island to the northeast parallel to the Aleutian trench axis, and turns in the direction of east-southeast at Prince William Sound (Fig. 1). A remarkable upheaval of $10 \mathrm{~m}$ is observed on Montague Island, which is considered to be due to a subsidiary surface faulting called the Patton Bay fault. For the horizontal displacements, it can only be said that the dominant movement at the triangulation points in the epicentral region is characterized by the direction of south-southeast and the magnitude of the order of $15 \mathrm{~m}$, since the measurements have been made only in the vicinity of Prince William Sound.

\subsection{Data parameters}

In the present inversion analysis, only the vertical displacement data are used, because of the inadequate accuracy of the triangulation data. A number 


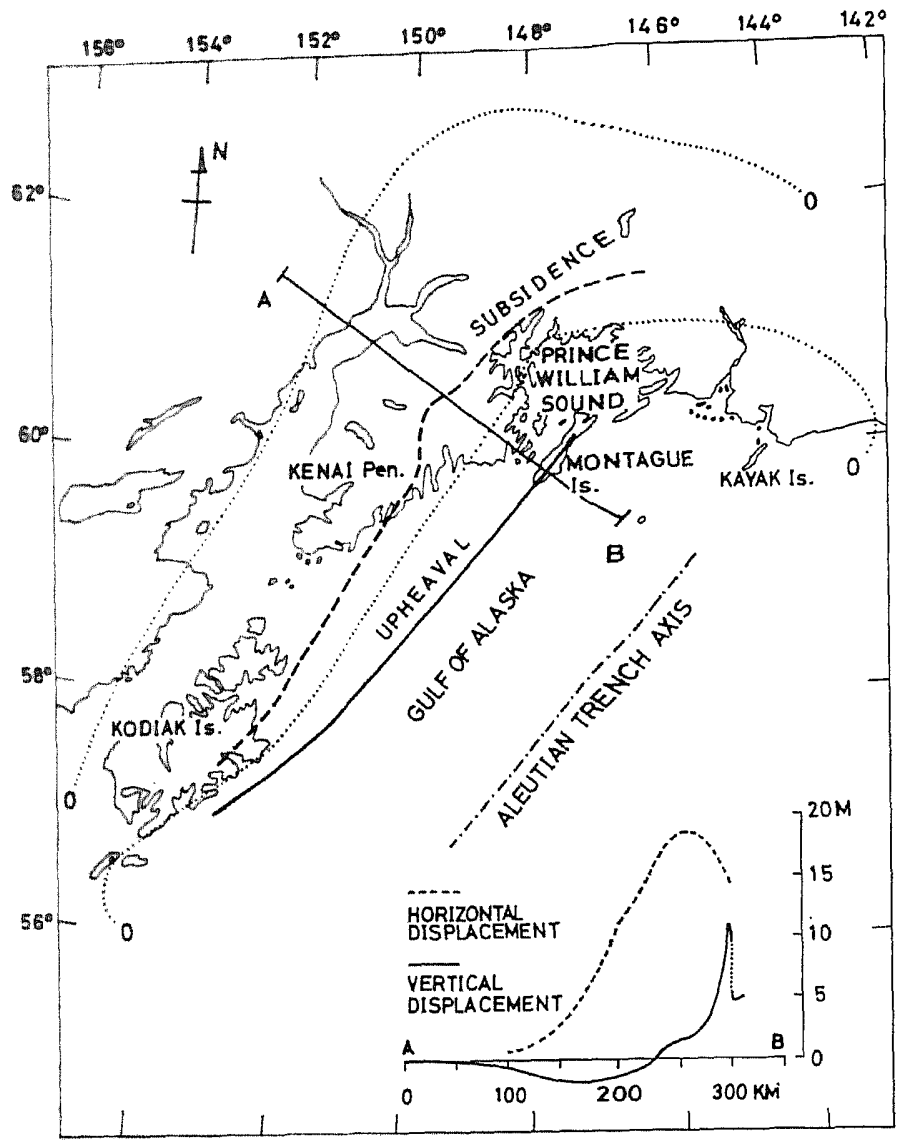

Fig. 1. Crustal deformations in south-central Alaska associated with the Alaska earthquake of 1964 (from PLAFKer, 1969). Solid and dashed lines indicate the axes of the maximum upheaval and subsidence respectively.

of data which can be treated in our computer program (MATSU'URA, 1977b) is limited to 300 by the capacity of the computer's memory, while the number of the observed data to be analyzed far exceeds this limitation. To overcome this trouble, the averaged value of several data at the observation points located in a square region is taken as a data parameter for the inversion analysis, where the dimensions of each square region are adopted as $5 \times 5,10 \times 10$ and $20 \times 20 \mathrm{~km}^{2}$, for the vicinity of the surface fracture, the region around the remarkable upheaval, and the other parts of the deformed area respectively (Fig. 2). Through the process of averaging mentioned above, numerous observed data are rearranged into a set of 280 data parameters. The predicted error associated with each data parameter is defined by

$$
\sigma_{i}=\sigma_{0}\left|o_{\max }\right|\left(1+\left|o_{i}\right| o_{\max } \mid\right) / 2 \quad(i=1, \ldots, 280),
$$




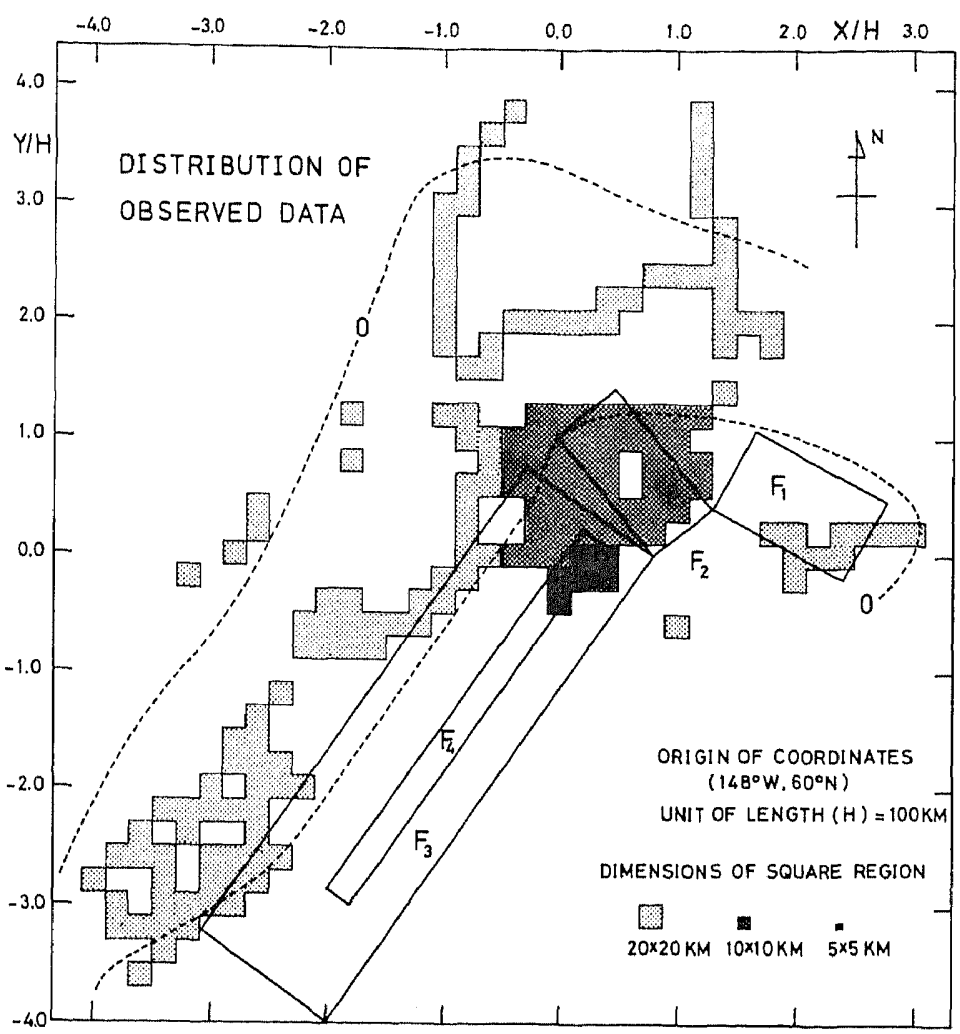

Fig. 2. Distributions of observed data. Stations where elevation changes have been reported are covered with shaded square regions with three different dimensions, $20 \times 20,10 \times 10$ and $5 \times 5 \mathrm{~km}^{2}$. Projection of the initial fault model for inversion analysis (Table 1) on the earth's surface is indicated by a set of four rectangles, $F_{1}, F_{2}, F_{3}$, and $F_{4}$.

where $\sigma_{0}$, the "error coefficient", is taken as 0.10 in the present analysis. The quantities, $o_{i}$ and $o_{\max }$, represent the $i$-th and the maximum data parameter respectively.

\subsection{Initial estimates of model parameters}

Taking account of the pattern of the deformation fields, the fracture system is modelled by a multiple-fault system composed of four rectangular faults $F_{1}, F_{2}, F_{3}$ and $F_{4}$, where each elemental fault is uniquely prescribed by a set of nine independent fault parameters as referred to in Fig. 3. As shown in Fig. 2, a set of faults, $F_{1}, F_{2}$ and $F_{3}$, which are jointed to each other at the fault corners, represents the main fracture system composed of the faulting in Kayak Island, Prince William Sound and Kodiak Island respectively. Fault $\mathrm{F}_{4}$ corresponds to the subsidiary surface faulting on Montague Island. 
Table 1. Presupposed conditions for analysis.

\begin{tabular}{|c|c|c|c|c|c|c|c|c|c|c|}
\hline & & $\delta$ & $\lambda$ & $D(\mathrm{~m})$ & $W(\mathrm{~km})$ & $d(\mathrm{~km})$ & $a_{0}$ & $b_{0}$ & $a_{1}$ & $b_{1}$ \\
\hline \multirow{4}{*}{$x_{j}{ }^{0}$} & $F_{1}$ & $40^{\circ} \mathrm{NE}$ & $120^{\circ}$ & 12.0 & 100.0 & 10.0 & 2.40 & -0.20 & 1.30 & 0.40 \\
\hline & $\mathrm{F}_{2}$ & $20^{\circ} \mathrm{NW}$ & $70^{\circ}$ & 14.0 & 140.0 & 10.0 & 1.30 & 0.40 & 0.80 & 0.00 \\
\hline & $\mathrm{F}_{3}$ & $20^{\circ} \mathrm{NW}$ & $60^{\circ}$ & 14.0 & 140.0 & 10.0 & 0.80 & 0.00 & -2.00 & -4.00 \\
\hline & $F_{4}$ & $40^{\circ} \mathrm{NW}$ & $60^{\circ}$ & 12.0 & 30.0 & 1.0 & 0.40 & 0.10 & -1.80 & -3.00 \\
\hline \multirow{4}{*}{$t_{j}$} & $\mathrm{~F}_{1}$ & 10.0 & $10.0^{\circ}$ & 2.0 & 20.0 & 2.0 & 0.20 & 0.20 & 0.10 & 0.10 \\
\hline & $F_{2}$ & $5.0^{\circ}$ & $5.0^{\circ}$ & 1.0 & 10.0 & 2.0 & 0.10 & 0.10 & 0.10 & 0.10 \\
\hline & $F_{3}$ & $5.0^{\circ}$ & $5.0^{\circ}$ & 1.0 & 10.0 & 2.0 & 0.10 & 0.10 & 0.20 & 0.20 \\
\hline & $F_{4}$ & $5.0^{\circ}$ & $5.0^{\circ}$ & 1.0 & 5.0 & 1.0 & 0.10 & 0.10 & 0.20 & 0.20 \\
\hline
\end{tabular}

Error coefficient: $\sigma_{0}=0.10$

$x_{j}{ }^{0}$, initial value of model parameter; $t_{j}$, maximum allowable deviation; $\left(a_{0}, b_{11}\right)$ and $\left(a_{1}\right.$, $\left.b_{1}\right)$, coordinates of upper fault corners taking an origin at $\left(148^{\circ} \mathrm{W}, 60^{\circ} \mathrm{N}\right)$ and unit in $100 \mathrm{~km}$. The other notations are referred to Fig. 3.
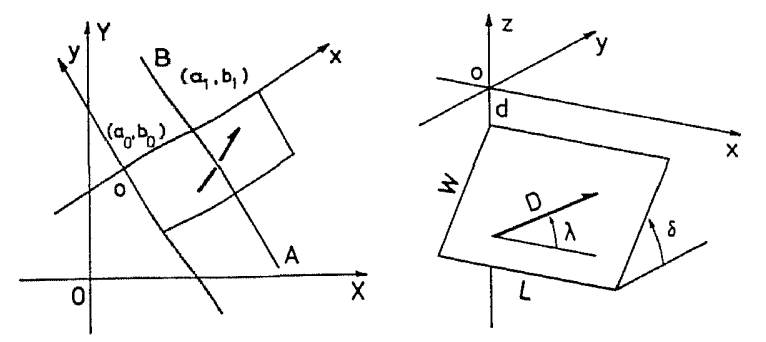

GEOMETRY AND NOTATION

D: DISLOCATION

$\delta$ : DIP-ANGLE

$\lambda$ : SLIP-ANGLE

W: FAULT WIDTH

L:FAULT LENGTH

$\left(a_{0}, b_{0}\right)$ AND $\left(a_{1}, b_{1}\right):$ LOCATION

OF UPPER FAULT CORNERS
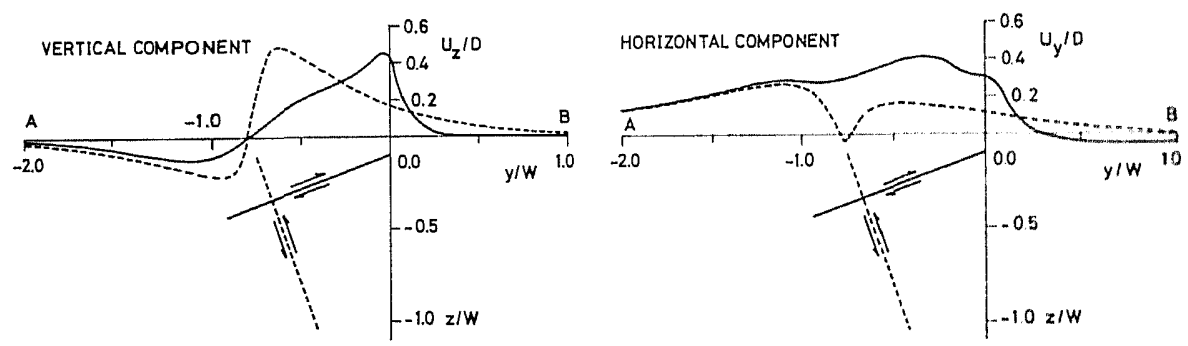

Fig. 3. Geometries of fault, notations of parameters and surface displacements due to typical fault models. Notations of model parameters for inversion analysis are given in the upper half of the figure, where coordinate system, $(x, y, z)$, is fixed to fault plane. Slip-angle $(\lambda)$ is measured counterclockwise from horizon on the fault plane. Parameters, $\left(a_{0}, b_{0}\right)$ and $\left(a_{1}, b_{1}\right)$, are denoted by the coordim nates, $(X, Y)$, of the upper fault corners. Vertical and horizontal displacements along A-B due to low-angle $\left(\delta=20^{\circ}\right.$, solid line) and high-angle $\left(\delta=70^{\circ}\right.$, dashed line) thrust model are shown in the lower half of the figure. 
The gross feature of the displacement profile at Montague Island (Fig. 1) seems to be interpretable by either the low-angle or high-angle fault model for the vertical component, but not for the horizontal component. According to the elastic dislocation theory, the profile of the horizontal displacement field due to the high-angle model has a distinctive feature which did not appear in the case of the event in 1964, such as the existence of a pronounced minimum point in a neighborhood of the intersection of the earth's surface and the extension of the fault plane (Fig. 3). On the basis of such a consideration, the low-angle underthrust type is taken as the initial model for the inversion analysis, and the initial estimates and "maximum allowable deviations" of the model parameters are given in Table 1. It should be noted that the final results of the analysis do not critically depend on the choice of these presupposed values (MATsu'URA, 1977b).

\subsection{Optimization of model parameters}

A practical method of finding an optimal fault-plane solution and evaluating the degree of its reliability from a set of inaccurate geodetic data has been developed in a previous paper (MATsu'URA, 1977a: referred to as Paper I hereafter). The outline of this method is given in the following part of the present section.

Consider a $n \times m$ linear system, which is already standardized by the predicted errors of the data parameters and the maximum allowable deviations of the model parameters,

$$
\Delta o=A \Delta x
$$

where $A$ is the coefficient matrix defined in section 3 of Paper I, and $\Delta o$ and $\Delta \boldsymbol{x}$ are the residual vector of the data parameter and the correction vector of the model parameter respectively. The inversion problem is to find the vector $\Delta \hat{\boldsymbol{x}}$ which minimizes simultaneously both $|\Delta o-A \Delta \boldsymbol{x}|$ and $|\Delta \boldsymbol{x}|$ under the conditions of $\sigma\left(\Delta \hat{x}_{j}\right) \leq 1(j=1, \ldots, m)$, where $\sigma\left(\Delta \hat{\boldsymbol{x}}_{j}\right)$ is the expected error of the $j$-th model parameter. By applying the "decomposition theorem" for an arbitrary rectangular matrix (LANCZOS, 1961) to the coefficient matrix, we get

$$
\boldsymbol{A}=\boldsymbol{U} \boldsymbol{\Lambda} \boldsymbol{V}^{\mathrm{t}}
$$

and the solution for such a problem is given in the following form,

$$
\Delta \hat{\boldsymbol{x}}=V \boldsymbol{\Lambda}^{-1} \boldsymbol{U}^{\mathrm{t}} \Delta \boldsymbol{o}
$$

where $A$ is a diagonal matrix with the non-zero elements of the $q(\leq m, n)$ positive eigenvalues of the coefficient matrix, and $U$ and $V$ are semi-orthonormal matrices constituted from the corresponding eigenvectors.

In the present study, the degree of the reliability of the solution is evaluated by the following quantities defined in terms of the corresponding elements 
of the above-mentioned vectors and matrices:

$$
\begin{array}{ll}
\text { resolution: } & r_{j}=\left[\sum_{l=1}^{m}\left(\sum_{k=1}^{q} V_{j k} V_{l k}-\delta_{j l}\right)^{2}\right]^{1 / 2}, \\
\text { expected error: } & s_{j} \equiv \sigma\left(\Delta \hat{x}_{j}\right)=\left[\sum_{k=1}^{q}\left(V_{j k} / \lambda_{k}\right)^{2}\right]^{1 / 2}, \\
\text { mean error: } & \sigma=\left[\sum_{i=1}^{n}\left(\Delta o_{i}-\sum_{j=1}^{m} A_{i j} \Delta \hat{x}_{j}\right)^{2}\right]^{1 / 2},
\end{array}
$$

where $\delta_{j l}$ is Kronecker's symbol. The degree of the reliability depends on both the resolution $r_{j}$ and expected error $s_{j}$. If both $r_{j}$ and $s_{j}$ are small enough, the estimated value of the $j$-th parameter is reliable. When the estimate is accompanied with a large value in both the resolution and expected error, we can only obtain a meaningless conclusion that the observed data contain little information on its parameter. As shown in 2.4 of Paper $I$, the quantity $\sigma$ has a particular meaning; that is the value of $\sigma$ gives us information on whether the analysis is consistent or not. If $1 / 2<\sigma<1$, the choice of the presupposed conditions is suitable for the model concerned.

In the case of the present section (analysis for multiple-fault system), the optimization of the model parameters is accomplished through a successive iteration of inversions, since the data parameters (static displacements) are related nonlinearly to the model parameters (fault parameters). On the other hand, in the case of the following section (analysis for dislocation profile), the successive iteration is not needed, because only the dislocation, which relates linearly to the data parameters, is taken as the variable parameter.

\subsection{Results of analysis}

The process of the optimization of the model parameters is completed at the sixth step of the successive iteration of the inversions. The final estimates are given in Table 2 with the corresponding resolutions $r_{j}$ and expected errors $s_{j}$, where $\left(a_{0}, b_{0}\right)$ and $\left(a_{1}, b_{1}\right)$ are the locations of the fault corners denoted by the coordinates with the origin at $\left(148^{\circ} \mathrm{W}, 60^{\circ} \mathrm{N}\right)$ and in units of $100 \mathrm{~km}$ (Fig. 2). As a whole, the results of the analysis are sufficiently reliable for the parameters concerned with $\mathrm{F}_{2}$ and $\mathrm{F}_{3}$, but not for those concerned with $F_{1}$ and $F_{4}$, because of the scarcity of the measurements in the Kayak Island region and of the lack of the data in the Gulf of Alaska respectively.

For the main fracture system, the predominant motion is a reverse dipslip along the Aleutian underthrust, and the total length and average width are about $600 \mathrm{~km}$ and $150 \mathrm{~km}$ respectively. The dip-angle $(\delta)$ and dislocation $(D)$ vary correspondingly to a change in the trend of the tectonic features, such as $\delta=20^{\circ} \mathrm{NE}$ and $D=8 \mathrm{~m}$ for $\mathrm{F}_{1}$ (Kayak Island region), $\delta=7^{\circ} \mathrm{NW}$ and $D=10 \mathrm{~m}$ for $\mathrm{F}_{2}$ (Prince William Sound region), and $\delta=25^{\circ} \mathrm{NW}$ and $D=19 \mathrm{~m}$ for $\mathrm{F}_{3}$ (Kodiak Island region). 
Table 2. Final estimates (Model I).

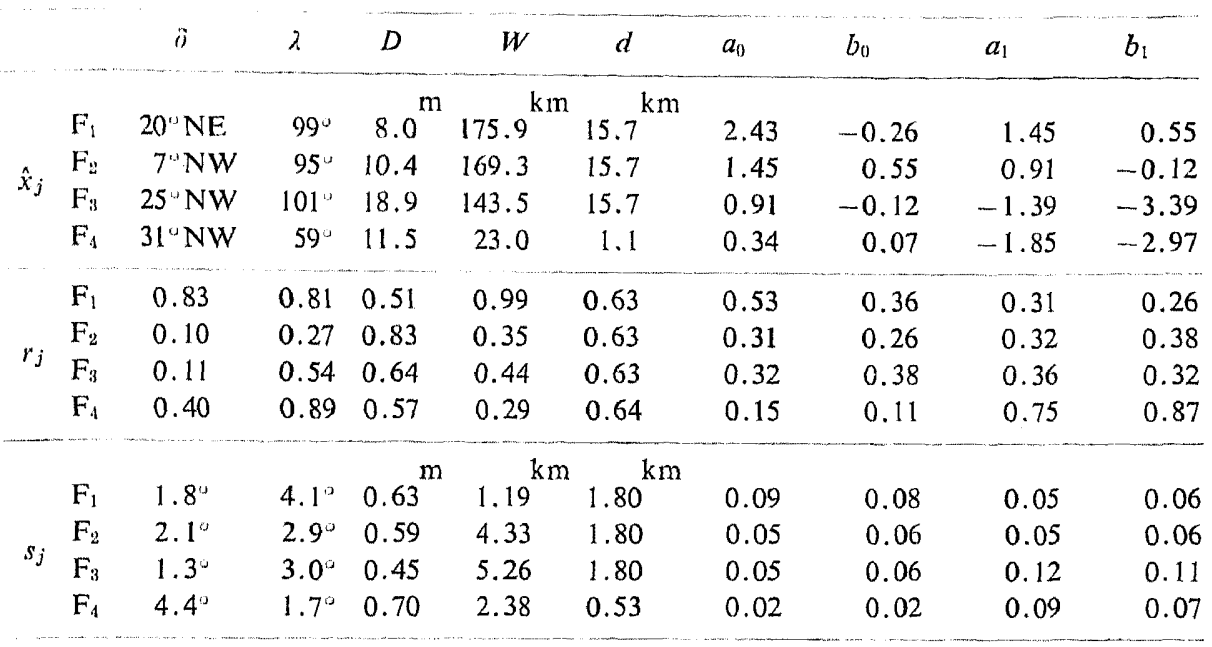

$\hat{x}_{j}$, optimal model parameter; $r_{j}$, resolution; $s_{j}$, expected error; $\left(a_{0}, b_{0}\right)$ and $\left(a_{1}, b_{1}\right)$, coordinates of upper fault corners taking an origin at $\left(148^{\circ} \mathrm{W}, 60^{\circ} \mathrm{N}\right)$ and unit in $100 \mathrm{~km}$. The other notations are referred to Fig. 3.

From the body wave data, Stauder and Bollinger (1966) and Harding and Algermissen (1969) have obtained the nodal-plane solutions. When we adopt a low-angle thrust model on the basis of the consideration for the pattern of the horizontal displacement field (refer to 2.2), the results of the body wave analysis indicate that the high-angle nodal-plane determined by these authors is the auxiliary plane, and the fault-plane is to be extremely low-angle, i.e. less than $10^{\circ}$, as pointed out by Hastie and Savage (1970). On the other hand, the long-period surface wave data prefer a somewhat high-angle $\left(20^{\circ}\right)$ thrust model (KANAMORI, 1970). This discrepancy is significant, because the dip-angle is the most sensitive parameter in the analysis. It is reasonable to consider that the differences between the result of the body wave analysis and that of the surface wave analysis come from the regional variation in the faulting mechanism of the extensive fracture system, since the $\mathrm{P}$-wave first motion and $\mathrm{S}$-wave polarization depend on only the nature of the initial portion of the faulting, while the total feature of the fracture system is reflected in the radiation of the long-period surface waves. The faulting mechanism proposed in the present analysis interprets well the discrepancy mentioned above, which indicates an extremely low-angle thrust in the Prince William Sound region where the initial faulting occurred and a somewhat high-angle thrust in the Kodiak Island region where the subsequent faulting occurred.

The subsidiary faulting $\left(F_{4}\right)$ is a reverse dip-slip with a small left-lateral 
component. The dip-angle and dislocation are estimated to be $31^{\circ} \mathrm{NW}$ and $12 \mathrm{~m}$ respectively. This fault extends from Kodiak Island to Montague Island with the dimensions of $380 \mathrm{~km}$ (length) $\times 23 \mathrm{~km}$ (width). The strike direction is $\mathrm{N} 36^{\circ} \mathrm{E}$ and parallel to that of $F_{3}$ (main fault in the Kodiak Island region). As shown in Table 2, the slip-angle and southwestern fault end are indefinite, because of the lack of the observed data.

The static displacement fields calculated for the optimal four-fault model (referred to as Model $\mathrm{I}$ hereafter) is shown in Fig. 4. The vertical components are well interpreted by Model I, where it should be noted that the mean error, which takes a value of 0.8 , satisfies the condition for the consistency of the analysis. As to the horizontal components, there exists a remarkable discrepancy between the observed and theoretical displacement fields, that is, the

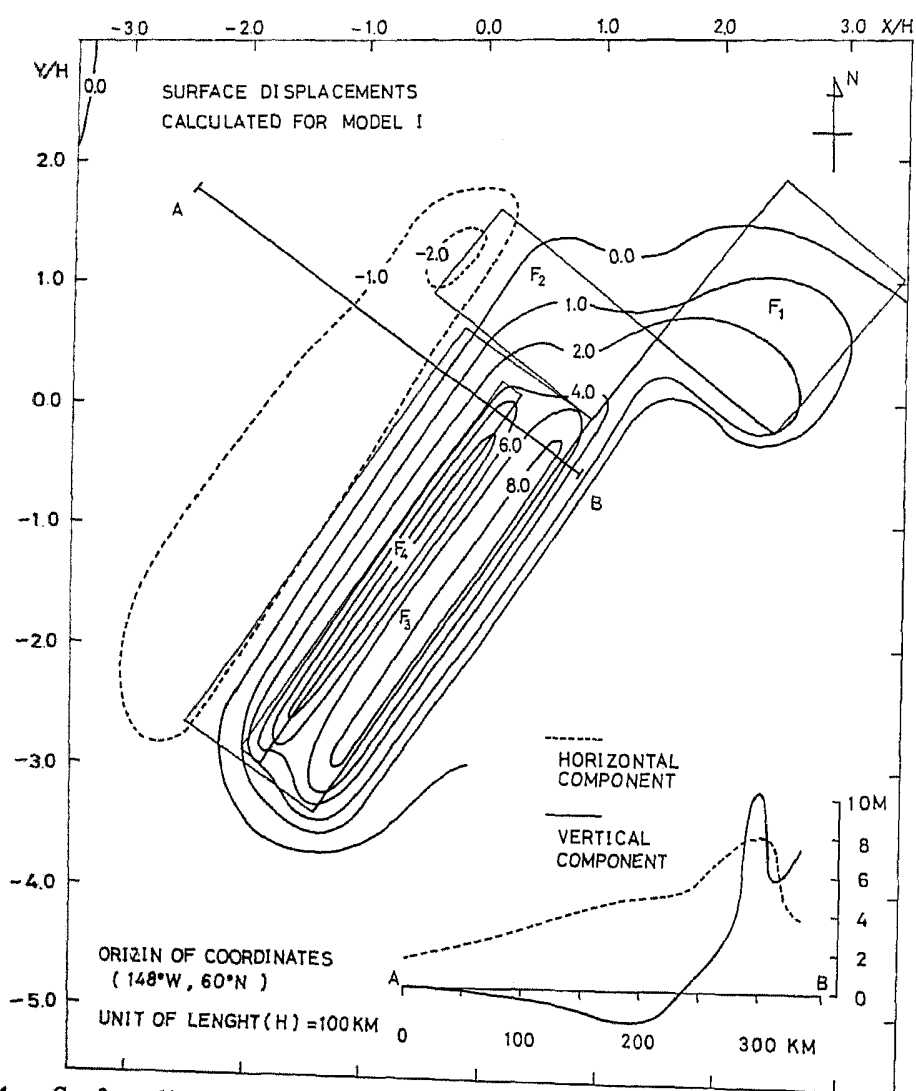

Fig. 4. Surface displacements calculated for Model I (optimal four-fault model).
The vertical displacement The vertical displacement field is represented by contour map (in meter), optimal four-fault model (Table $F_{2}$ ) $F_{3}$ and $F_{4}$, indicates the projection of the along $\mathrm{A}-\mathrm{B}$ are shown in the lower part of the surface. The displacements 
observed data in the epicentral region are of the order of $15 \mathrm{~m}$, while the theoretical values are less than $10 \mathrm{~m}$. This difference in magnitude seems to be far beyond the order of the observational error. We cannot denny a possibility that the data involve a systematic error due to the change in location of the temporary stable-points of the triangulation network, but the extent of the network is too poor to discuss it. In the following section, another possibility is briefly discussed by taking account of an effect of the dislocation varying on a curved fault surface, which is neglected in the present multiplefault modelling.

\section{Finite-Element Analysis for Dislocation Profile}

In the analysis of the preceding section, it has been assumed that the dislocation is uniform over each fault plane in a homogeneous half-space. In reality, the medium is not homogeneous, but has a complicated geologic structure. The real fracture system would be expected to consist of several complex faults, on which the dislocation varies in some continuous manner. However, it is meaningless to deal with such a complex and realistic model as it is in the framework of the inversion analysis, because the observed data are always finite in the number and extent, and because they contain random errors. Our concerns in the present section are restricted to the determination of the dislocation profile along the fault from the displacement data.

According to the results of the inversion analysis for the multiple-fault system, in the Kodiak Island region, the fault motion is predominantly underthrust for either of the main $\left(F_{3}\right)$ and subsidiary $\left(F_{4}\right)$ fault. The ratio of the length to width is 2.8 for $F_{3}$ and 16.0 for $F_{4}$. The strike directions of these two faults coincide with each other, i.e., those are parallel to the Aleutian trench axis. The conditions mentioned above indicate that it is allowable to apply a two-dimensional approximation to the modelling of the fracture system in the Kodiak Island region. Setting a vertical section, A-B, to be perpendicular to the strike direction (Fig. 4), the problem is treated in a framework of a plane-strain, finite-element approximation.

\subsection{Plane-strain, finite-element modelling}

The finite-element technique is a convenient tool to deal numerically with a complex faulting in a complicated structural medium. The theory and application of the finite-element method are found in many engineering literatures. Here, we outline the basic idea to simulate the faulting in the finite-element framework following the study of JUNGELS and FrazIER (1973).

Consider the fault to be a discontinuity in a displacement field. Simulating the dislocation surface (S) by a sequence of the double nodes bifurcated 
to the upper- and lower-node, the faulting on $S$ is defined by prescribing a relative displacement vector $\left(D_{i}\right)$ tangent to $S$ to the $i$-th pair of nodes, that is

$$
U_{i}^{(+)}-U_{i}^{(-)}=D_{i},
$$

where $U_{i}^{(+)}$and $U_{i}^{(-)}$denote the displacement vectors at the upper- and lowernode of the $i$-th pair respectively. It should be noted that under the planestrain approximation, the relative displacement vectors are also to be in the plane of constant strain. In the present simulation, the condition of traction continuity across the dislocation surface is replaced by that between the upper- and lower-node which face each other across $S$;

$$
F_{i}^{(+)}+F_{i}^{(-)}=0 \text {, }
$$

where $\boldsymbol{F}_{i}^{(+)}$and $\boldsymbol{F}_{i}^{(-)}$are the traction acting on the upper- and lower-node of the $i$-th pair respectively. It is assumed that the condition of traction continuity is maintained even after the occurrence of a faulting, because the relative displacements are extremely small compared with the dimensions of the triangular elements used for the modelling.

The simulation of a dislocation surface described above is applied to the modelling of the fracture system in the Kodiak Island region, which consists of a main faulting along the Aleutian underthrust and a subsidiary surface faulting on Montague Island. The finite-element mesh for a rectangular

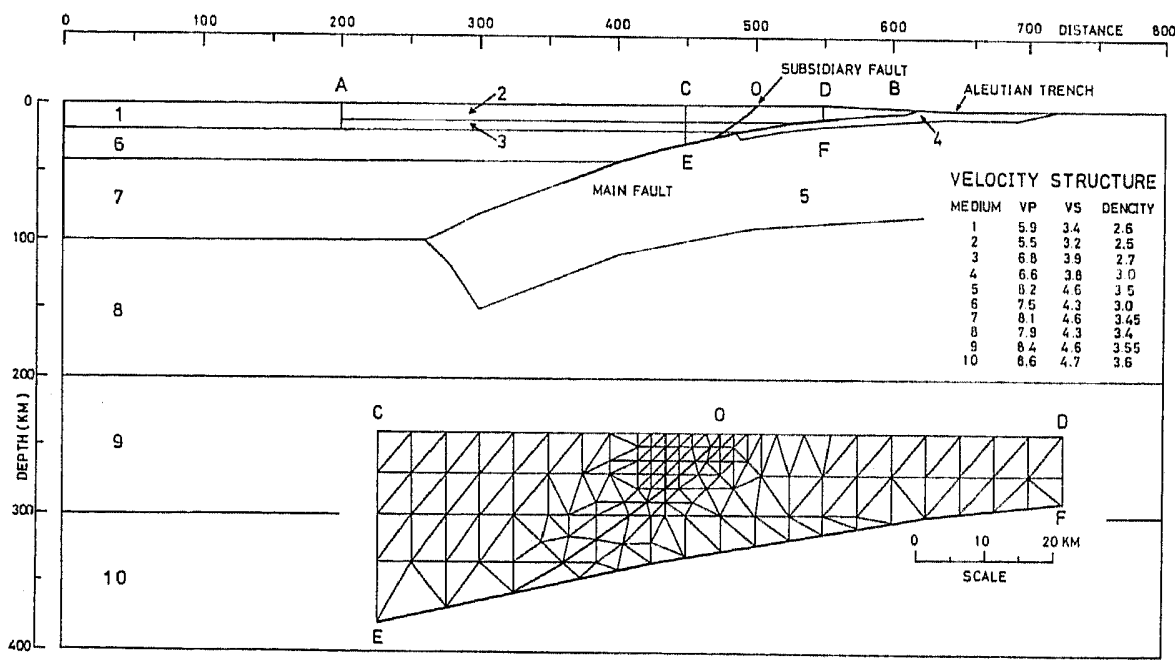

Fig. 5. Finite-element mesh and structural model. The finite-element mesh used in the present study is shown for only the neighboring region of faults, C-E-F-D, where the fault surfaces are denoted by heavy solid-lines. The elastic parameters, $V \mathrm{P}$ (P-wave velocity in $\mathrm{km} / \mathrm{s}$ ), $V \mathrm{~S}$ (S-wave velocity in $\mathrm{km} / \mathrm{s}$ ), and $\mathrm{DEN}$ SITY (density in $\mathrm{gr} / \mathrm{cm}^{3}$ ), in each tectonic region are tabulated in the righthand corner. 
vertical section which includes the fracture system is given in Fig. 5, where the region with dimensions of $400 \times 800 \mathrm{~km}^{2}$ is covered with about 800 triangular elements. The main fault is represented by a sequence of 25 double nodes along the curved tectonic boundary between the continental and oceanic plates. The dip-angle gradually increases along the dislocation surface from $10^{\circ}$ at its upper margin to $25^{\circ}$ at its lower end. The subsidiary dislocation surface, which is simulated by a sequence of 9 double nodes, extends from the earth's surface up to a depth of $24 \mathrm{~km}$ with a dip-angle $50^{\circ}$ at its upper margin and $35^{\circ}$ at its lower end. The geometries of the dislocation surfaces are determined by taking the results obtained in the preceding section into consideration. The structural model used in the present study is composed of 10 geologic blocks, where the crustal structure is determined on the basis of the seismic refraction studies by SHOR (1962) and HALES and ASADA (1966), and the elastic parameters of the upper mantle are based on the estimates by ARCHAmbeau et al. (1969) and Simpson et al. (1974).

\subsection{Optimal dislocation profile}

The levelling data at the observation points close to the vertical section, A-B, are rearranged into a set of 36 data parameters, where the interval of the adjacent data points is taken to be proportional to the inverse of the displacement gradient. The predicted errors associated with these data parameters are detined in the same manner as in 2.1. As a model parameter for the inversion analysis, we take the dislocation assigned to each of the double nodes which constitute a dislocation surface, where the positive value corresponds to a reverse dip-slip motion. Since the static displacements are linearly related to the dislocations, the optimization of the model parameters is accomplished through a single process of the inversion outlined in 2.3. It should be noted that the $i j$ element of the coefficient matrix is given by a vertical displacement at the $i$-th data point due to the unit dislocation on the $j$-th double node.

To achieve a good accuracy in the finite-element approximation, an especially fine mesh of the triangular elements should be used in the proximity of the faults as shown in Fig. 5, while such a fine modelling brings about a difficulty to obtain a good resolution in the estimation of the model parameters. To overcome the dilemma mentioned above, we adopt an averaged dislocation in place of several dislocations accompanied by bad resolutions as a variable parameter in the actual inversion analysis. As a result of such a treatment, the number of the independent model parameters is reduced from 25 to 15 for the main fault and from 9 to 6 for the subsidiary fault.

The results of the inversion analysis of the dislocations are given in Fig. 6 , where the abscissa is the distance along each fault surface from its upper 


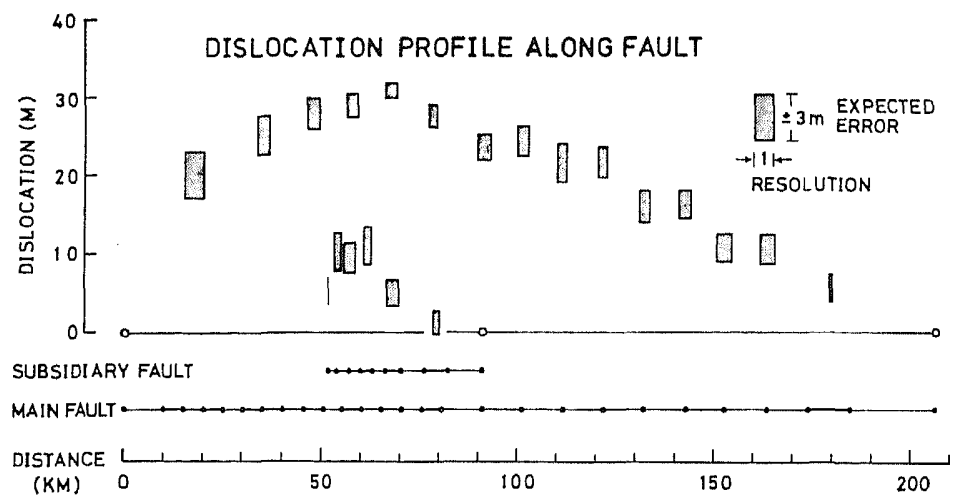

Fig. 6. Dislocation profile along fault surface. The estimated dislocations on each of the main and subsidiary fault are represented as a function of the distance along the fault surface from its upper margin. Large open-circles, which correspond to the fault margins, indicate that the dislocations are fixed to zero at those points in the present analysis. Small open-circles denote the double nodes which constitute a dislocation surface in the finite-element modelling. In spite of the dislocations on the double nodes which are jointed to each other by heavy solid lines, an averaged dislocation is adopted as a variable parameter in the present inversion analysis.

margin. The resolution and expected error are denoted by the width and hight of the corresponding rectangle respectively, i.e., if the area of a rectangle is small enough, the estimated value is regarded as reliable. For the main fault, the dislocation function has a broad peak at a depth of about $20 \mathrm{~km}$ under Montague Island, and decreases monotonously to zero at the lower fault end. The faulting does not extend up to a depth of $60 \mathrm{~km}$. In the present analysis, the upper fault margin is indefinite, because of the lack of the data in the Gulf of Alaska. For the subsidiary fault, the estimated dislocation profile is in accord with the general feature of surface faulting pointed out by MikUMO (1973), i.e., the dislocation takes its maximum value $(12 \mathrm{~m})$ close to the earth's surface, and decreases steeply with depth. From such a profile, it can be concluded that the subsidiary faulting does not reach the main fault. The effective fault-width, which is defined as the width of the section accompanied by a pronounced dislocation, is roughly estimated to be 150 and $20 \mathrm{~km}$ for the main and subsidiary fault respectively. The average dislocation for each effective fault-width is calculated to be about $20 \mathrm{~m}$ for the main fault and $10 \mathrm{~m}$ for the subsidiary fault. These results almost agree with those in the preceding section (Table 2), where the fracture system in the Kodiak Island region is represented by the two rectangular faults, $F_{8}$ and $F_{4}$. It is reasonable that the effective fault-width and average dislocation are approximately the same as the fault width and dislocation determined from the rectangular fault with a uniform dislocation. 


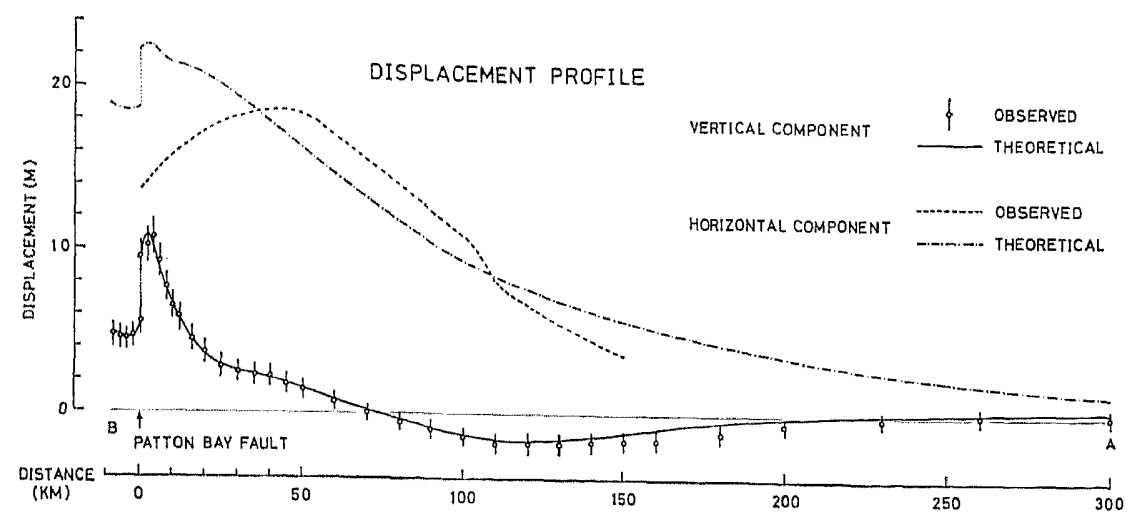

Fig. 7. Profiles of the observed and calculated surface displacements across the strike of the fracture system in the Kodiak Island region. For the vertical components, the predicted errors of data defined in 2.1 of this paper are given by the corresponding error bars. The observed data adopted are based on PLAFKer (1969) and PARKIN (1966) for the vertical and horizontal displacements respeclively.

The static displacements calculated for the finite-element fault model with the optimal dislocation profile (referred to as Model II hereafter) are shown in Fig. 7. The observed displacements are well interpreted by Model II not only for the vertical components but also for the horizontal components. It should be noted that for Model I, which has a uniform dislocation over the whole of a rectangular fault plane, the horizontal displacements are pretty small compared with the observed data (Fig. 4). It is an interesting result that the discrepancy between the observed data and theoretical values for Model I is almost resolved in the case of Model II, in which the dislocation along the main fault has a broad peak on the more loosely-dipping section of the curved fault surface. To interpret well both the vertical and horizontal displacement fields due to a faulting along the Aleutian underthrust system, it seems necessary to take account of the effect of the dislocation varying on a curved fault surface.

\section{Conclusions}

The faulting mechanism of the great Alaska earthquake of 1964 has been investigated in detail by applying the inversion technique to the observed static-displacement data. Dealing with the extensive fracture system, it is necessary to take account of the regional variation in the faulting mechanism, since the nature of the faulting clearly depends on the tectonic features of the region concerned.

In the present study, the whole of a fracture system was represented by 
the four-fault model at first (section 2). The difference between the dip-angles determined from the body-wave and surface-wave data respectively is well interpreted by the optimal four-fault model, which shows the extremely lowangle $\left(7^{\circ}\right)$ thrust motion in the Prince William Sound region and somewhat high-angle $\left(25^{\circ}\right)$ thrust motion in the Kodiak Island region.

Second, the fracture system in the Kodiak Island region is represented by the plane-strain, finite-element model on the basis of the results of the analysis for the four-fault model (section 3). From the finite-element analysis, it was found that the Patton Bay fault, which has the greatest motion close to the earth's surface, does not reach the Aleutian underthrust. For the main fault, the dislocation takes the broad peak of the order of $30 \mathrm{~m}$ on the more loosely-dipping section (under Montague Island) of the curved fault surface. Both the vertical and horizontal displacements observed are well interpreted by the present finite-element model with such a dislocation profile.

The authors are indebted to Dr. R. Sato for critically reading the manuscript and offering useful suggestions.

The computations involved were made on HITAC 8700 and 8800 at the Computer Center, University of Tokyo.

\section{REFERENCES}

Alewine, R. W., Application of linear inversion theory toward the estimation of seismic source parameters, Ph. D. Thesis, CIT, 303 pp., 1974.

ALEWINE, R. W. and T. H. JORDAN, Generalized inversion of earthquake static displacement fields, Geophys. J. R. Astron. Soc., 35, 357-361, 1973.

Archambeau, C. B., E. A. Flinn, and D. G. Lambert, Fine structure of the upper mantle, J. Geophys. Res., 74, 5825-5865, 1969.

Ben-Menahem, A., M. Rosenman, and M. IsRael, Source mechanism of the Alaska earthquake of 1964 from amplitudes of free oscillations and surface waves, Phys. Earth Planet. Inter., 5, 1-29, 1972.

HALes, A. L. and T. ASADA, Crustal structure in coastal Alaska; The earth beneath the continents, ed., J. S. Steinhart and T. J. Smith, Geophys. Mon. Ser., 10, 420-432, 1966.

Harding, S. T. and S. T. Algermissen, Focal mechanism of the Prince William Sound, Alaska earthquake of March 28, 1964, Bull. Seismol. Soc. Am., 59, 799-811, 1969.

Hastie, L. M. and J. C. Savage, A dislocation model for the 1964 Alaska earthquake, Bull. Seismol. Soc. Am., 60, 1389-1392, 1970.

JACKSON, D. D., Interpretation of inaccurate, insufficient and inconsistent data, Geophys. J. R. Astron. Soc., 28, 97-109, 1972.

JACKSON, D. D., Marginal solution to quasi-linear inverse problem in geophysics: The edgehog method, Geophys. J. R. Astron. Soc., 35, 121-136, 1973.

JUNGels, P. H. and G. A. FRAzrer, Finite element analysis of the residual displacements for an earthquake rupture: Source parameters for the San Fernando earthquake, J. Geophys. Res., 78, 5062-5083, 1973.

KANAMORI, H., The Alaska earthquake of 1964: Radiation of long-period surface waves and source mechanism, J. Geophys. Res., 75, 5029-5040, 1970. 
Lanczos, C., Linear Differential Operators, Chap. 3, 100-162, D. Van Nostrand Co., London, 1961.

Matsu'ura, M., Inversion of geodetic data. Part I. Mathematical formulation, J. Phys. Earth, 25, 69-90, 1977a.

Matsu'Ura, M., Inversion of geodetic data. Part II. Optimal model of conjugate fault system for the 1927 Tango earthquake, J. Phys. Earth, 25, 233-255, 1977b.

McCowan, D. W., P. Glover, and S. S. Alexander, A static and dynamic finite element analysis of the 1971 San Fernando, California, earthquake, Geophys. J. R. Astron. Soc., 48, 163-185, 1977.

Mrkumo, T., Faulting process of the San Fernando earthquake of February 9, 1971 inferred from static and dynamic near-field displacements, Bull. Seismol. Soc. Am., 63, 249-269, 1973.

Parkin, E. J., Alaskan survey to determine crustal movements. Part II. Horizontal displacement, U. S. Coast Geodet. Surv. Rep., 1966.

Plafker, G., Tectonic deformation associated with the 1964 Alaska earthquake, Science, 148, 1675-1687, 1965.

Plafker, G., Tectonics of the March 27, 1964 Alaska earthquake, U. S. Geol. Surv. Prof. Pap., 543-I, 1969.

Press, F. and D. JACKSON, Alaska earthquake, 27 March 1964: Vertical extent of faulting and elastic strain energy release, Science, 147, 867-868, 1965.

Savage, J. C. and L. M. Hastie, Surface deformation associated with dip-slip faulting, $J$. Geophys. Res., 71, 4897-4904, 1966.

Shor, G. G., Seismic refraction studies off the coast of Alaska: 1956-1957, Bull. Seismol. Soc. Am., 52, 37-57, 1962.

Simpson, D. W., R. F. Merew, and D. W. King, An array study of P-wave velocities in the upper mantle transition zone beneath northeastern Australia, Bull. Seismol. Soc. Am., 64, 1757-1788, 1974.

STAuder, W. and G. A. Bollinger, The focal mechanism of the Alaska earthquake of March 28, 1964, and of its aftershock sequence, J. Geophys. Res., 71, 5283-5296, 1966.

Wiggins, R. A., The general linear inverse problem: Implication of surface waves and free oscillations for the earth structure, Rev. Geophys. Spac. Phys., 10, 251-285, 1972.

Wyss, M. and J. N. BRUNE, The Alaska earthquake of 28 March 1964: A complex multiple rupture, Bull. Seismol. Soc. Am., 57, 1017-1023, 1967. 